\title{
Discussion Paper \\ Modern Income-Share Agreements in Postsecondary Education: Features, Theory, Applications
}

Dubravka Ritter

Federal Reserve Bank of Philadelphia

Consumer Finance Institute

Douglas Webber

Temple University and

Federal Reserve Bank of Philadelphia

Consumer Finance Institute Visiting Scholar
DP 19-06

December 2019

https://doi.org/10.21799/frbp.dp.2019.06 


\title{
Modern Income-Share Agreements in Postsecondary Education: Features, Theory, and Applications
}

\author{
Dubravka Ritter* \\ Consumer Finance Institute, Federal Reserve Bank of Philadelphia \\ Douglas Webber $\dagger$ \\ Department of Economics, Temple University
}

December 2019

\begin{abstract}
An income-share agreement (ISA) in postsecondary education is a contract in which students pledge to pay a certain percentage of their future incomes over a set period of time in exchange for funding educational program expenses in the present. Typically, participants begin to make payments once their incomes rise above a minimum threshold set by the terms of the ISA and will never pay more than a set cap (usually, a multiple of the original amount). Funding for ISAs can range from university sources to philanthropic funding and private investor capital. In this study, we describe the many varied and often complex incarnations of ISA contracts, as well as their many use cases in traditional college programs, nondegree/certificate programs, and workforce development settings. First, we discuss the current state of the nascent ISA marketplace, including how ISAs are structured and funded, how educational programs come to consider offering ISAs to students, and what factors they might weigh during the ISA design and implementation stages. Second, we discuss the benefits and disadvantages of each major aspect of an ISA (e.g., funding model, payment terms) to students, institutions, and — if applicable — investors. Finally, we discuss the theoretical underpinnings of ISAs and the main practical challenges that institutions offering ISAs, students choosing these contracts, and regulators face in both the short and the long term as ISAs promulgate.
\end{abstract}

Keywords: income-share agreement, ISA, student loan, student debt, student loan repayment, higher education, income-driven repayment, IDR, income-based repayment, IBR, income-contingent loans, income-contingent repayment, ICR

JEL Classification Numbers: D18, D82, G23, G28, I22, I23, I26

* Federal Reserve Bank of Philadelphia, Ten Independence Mall, Philadelphia, PA 19106-1574; email: dubravka.ritter@phil.frb.org.

$\dagger 1301$ Cecil B. Moore Ave., Philadelphia, PA 19122; email: douglas.webber@temple.edu.

Disclaimer: This Philadelphia Fed Discussion Paper represents preliminary research that is being circulated for discussion purposes. The views expressed in these papers are solely those of the authors and do not necessarily reflect the views of the Federal Reserve Bank of Philadelphia or the Federal Reserve System. Nothing in the text should be construed as an endorsement of any organization or its products or services. No statements here should be treated as legal advice. Any errors or omissions are the responsibility of the author. Philadelphia Fed Discussion Papers are free to download at https://philadelphiafed.org/consumer-finance-institute/publications. 


\section{Introduction}

As the national student loan portfolio, currently at $\$ 1.6$ trillion, continues to grow steadily, many families are feeling the burden of the debt taken out to support postsecondary education. Student loan delinquency rates are stubbornly high, relative to other loan products, despite nearly one-third of borrowers and half of the dollars in the federal student loan program having reduced payments in various income-driven repayment (IDR) plans. Navigating student loan repayment has become increasingly challenging, with multiple repayment and forgiveness plans for federal loans (which account for most of the loan market) and a complex, sclerotic student loan servicing environment. It is no surprise that policymakers and other stakeholders in our higher education system are eager to find less burdensome and simpler ways to support families' investment in postsecondary education and training.

Yet, despite soaring student debt, the college premium to the average graduate is more than enough to justify the increasing price tag of a degree. But the downside risk of attending college — that is, the risk of not completing or failing to realize a higher income after graduation - has also increased over time, together with college tuition, particularly for low-income/wealth, minority, and nontraditional college students. ${ }^{1}$ Meanwhile, apprenticeships, skills-based training programs, and other lower-cost alternatives to traditional college enrollment are becoming more popular. This is no doubt at least in part because of the increasing cost of and borrowing for college, but also because of an increased focus on recredentialing and lifelong learning, often outside of traditional higher education settings.

Together, these factors have led to a rapidly expanding market for income-share agreements (ISAs) as tools to finance all or part of both traditional college degrees and nondegree postsecondary programs. As of this writing, over 40 colleges and universities, as well as numerous alternative education, vocational, recredentialing, and workforce development programs, have offered ISAs as an option for financing educational expenses. The ISA space is home to an array of firms, such as Better Future Forward, Leif, and Vemo Education, specializing in the design, implementation, servicing, or management of ISA programs, in partnership with educational institutions and investment firms. Additionally, several companies — such as Blair, Lumni, and Stride Funding (formerly AlmaPact) have offered direct-to-student ISAs without an educational program as an intermediary. ${ }^{2}$ ISAs are offered

\footnotetext{
${ }^{1}$ The National Center for Education Statistics defines nontraditional students as meeting one of seven criteria: enrolled in postsecondary education with a delay; attend college part-time; work full-time while attending school; are financially independent for financial aid purposes; have (nonspouse) dependents; are single parents; or do not have a high school diploma. See, e.g., https://nces.ed.gov/pubs/web/97578e.asp.

${ }^{2}$ Some direct-to-consumer providers partner with educational programs to reach prospective applicants and assess educational program quality. According to market participants, there are only about 100 outstanding direct-to-
} 
by some postsecondary institutions as a way to extend institutional resources or as an alternative to student loans (usually, but not always, private student loans). At other institutions, ISAs are one type of education financing for those students who are ineligible for federal student lending or whose programs of study do not participate in the federal loan program.

In its simplest incarnation, an ISA is a contract that obligates students to pay a certain percentage of their future incomes over a set period of time (up to a set number of payments) in exchange for funding for educational expenses in the present. ${ }^{3}$ Typically, participants begin to make payments once their incomes rise above a minimum threshold set by the terms of the ISA and will never pay more than a set cap (usually, a multiple of the original funding amount). ${ }^{4}$ There are three ways to satisfy an ISA obligation: 1) reach the payment cap, 2) make the required number of monthly payments at the required income share (with payments due in periods in which income exceeds the minimum income threshold and not otherwise deferred), or 3 ) reach the end of the maximum payment window. A variety of sources can provide funding for educational expenses, including the educational programs themselves, private investors, employers, or - hypothetically - government entities. As the awareness of ISAs has increased, there has been substantial interest in these financial contracts from a wide variety of higher education stakeholders. The many varied and often complex incarnations of these ISA contracts, as well as their many use cases in traditional college programs, skills-based learning, vocational training, and workforce development settings, are the subject of this study.

As economists who have dedicated much of our professional careers to studying optimal financial aid systems, we find the complexities, incentives, promises, and potential pitfalls associated with ISAs to be fascinating both on a practical and an intellectual level. In this study, we explore three sets of questions. First, we give readers a sense of the current state of the nascent ISA marketplace. How are ISAs structured and funded? How do educational and vocational programs consider offering ISAs to students, and what factors do they weigh during the design and implementation stages? Second, for each

\footnotetext{
student ISA contracts in the marketplace today, although that number is rising rapidly. We focus primarily on school-based ISAs in this paper, but we also discuss ways in which direct-to-student ISAs work differently, wherever possible.

${ }^{3}$ Throughout this paper, "educational expenses" refer to the total cost of attendance: tuition, fees, room, board, and any other allowable expenses.

${ }^{4}$ For example, students may receive $\$ 10,000$ in funding toward college expenses in exchange for $2 \%$ of their income over 10 years or 120 payments. (Under some ISAs, the payment window could be extended for permissible grace/deferment/forbearance, such as enrollment in additional postsecondary training, so students could be making payments more than 10 years.) No payments would be due in months in which students earned less than the equivalent of $\$ 30,000$ per year before taxes $(\$ 2,000$ per month). No further payments would be required once the participant reaches two times $(2 \mathrm{X})$ the original amount of funding (i.e., $\$ 20,000)$, even if this occurred before the end of the payment window.
} 
major aspect of an ISA (e.g., funding model, payment terms), what are the theoretical costs and benefits to students, institutions, and funders, if applicable? Finally, going forward, what are the main practical challenges that institutions offering ISAs, students choosing these contracts, and regulatory agencies supervising ISAs face in both the short and long term?

One of the major challenges in the ISA space for industry participants, regulatory agencies, researchers, and consumer advocates examining the industry is the uncertainty in the legal and regulatory treatment of ISAs, especially relating to consumer financial protection regulations (e.g., fair lending laws). ${ }^{5}$ Whether or not ISAs are treated as loans (and plan sponsors/investors as lenders), or instead as nonloan financial contracts, has significant repercussions for the types of laws and regulations that would apply to ISAs. Generally speaking, if ISAs are not considered loans, the compliance framework for ISAs is significantly less stringent (particularly at the state level, where substantive regulation of lending, such as usury laws, would likely not apply). Industry participants and institutions offering ISAs have consistently argued that ISAs are not loans, but rather debt obligations or equity contracts that merit ISAspecific, tailored laws and regulations addressing the unique features of these financial instruments, some of which by design can avoid certain pitfalls that may arise for loans. Consumer advocates, on the other hand, have generally asserted that ISAs are either loans or loan-like enough products to be subject to some of the same regulations as student loans, via application of the existing regulatory framework or ISA-specific regulations that closely mimic loan regulations.

Because we are not legal experts, we take no position on this issue and use loan-agnostic terminology through our paper, given that no court or regulatory agency, to our knowledge, has deemed an ISA a loan so far. That said, we support consumer protections (e.g., nondiscrimination requirements) for ISA participants that are substantively comparable to those available to student loan borrowers. We acknowledge, at the same time, that many laws applicable to student loans, as written, are not necessarily conducive to being applied to a contract such as an ISA. We also recognize that ISAs by design — like other income-contingent financing vehicles - provide some protections for students who are more at risk of being paid a lower wage because payments are pegged to ex-post incomes. A well-designed set of consumer protection regulations certainly could balance the need for thoughtful oversight with sensible rules and procedures suitable to ISA-type financial contract.

This study would not have been possible without the generosity of insights from many individuals in the ISA space, from universities, vocational and workforce development programs, consulting firms, think tanks, consumer groups, law firms, legislative bodies, and investment firms. We

\footnotetext{
${ }^{5}$ For a discussion of the politics and policy of ISAs, see, e.g., Bair and Cooper (2019).
} 
are deeply indebted to these individuals for their time and expertise and are pleased to share the lessons we learned from our conversations through the publication of this study. In cases in which we discuss details that are publicly available, we identify the institution/organization by name. When citing examples that are not widely known to the general public, we do not cite a specific source. We chose this approach to encourage candor, and sometimes to protect the intellectual property, of the participants who agreed to speak with us. We also incorporated selected insights from the Consumer Finance Institute's recent symposium, Income-Share Agreements: Fundamentals, Evidence, and Considerations for the Future, on October $16 .{ }^{6}$

\section{A (Brief) History of Income-Share Agreements in the United States}

\section{II.A. Income-Contingent Repayment and Seeds for the Modern ISA Model}

In most cases, extending credit to students is a risky business because - unlike cars or houses - college degrees are not collateral to be reclaimed by a lender in case of repayment issues. Students, especially younger students, also face a high degree of uncertainty over future earnings. As a result, the private loan market is likely to substantially underinvest in education. ${ }^{7}$ Throughout history, societies therefore have injected public funds into education systems, including higher education. Early public sector solutions to the market failure in higher education in the decades after World War II involved federal loan guarantees for educational expenses and featured mortgage-style, fixed payments over a set period of time. Shireman (2017) details how income-contingent loan repayment and participation shares in future incomes cropped up in discussions of higher-education funding again and again in the 1960s and 1970s at the federal, state, and institutional levels. ${ }^{8}$ In fact, several prominent universities - Duke, Harvard, and Yale ${ }^{9}$ — attempted

\footnotetext{
${ }^{6}$ For more information on the symposium, including the agenda, visit https://philadelphiafed.org/consumer-financeinstitute/events/2019/modern-income-share-agreements.

${ }^{7}$ Palacios (2018) and Shireman (2017), among others, have recently discussed this phenomenon in greater detail.

${ }^{8}$ We use a number of terms in this paper for programs that all exhibit the same core feature: pegging payments to the student's postattendance income. "Income-contingent repayment" refers to the general principle of tying payments to income; in its broadest incarnation, it encompasses all of the specific varieties of student loan repayment or ISA payment plans, unless we refer specifically to the 1994 Income-Contingent Plan for Direct Loans. Income-driven and income-based plans are offered, in various forms, by the federal government in the United States today, and we refer to them collectively as IDR programs. Finally, ISAs are the form of income-contingent education financing we focus on in this paper.

${ }^{9}$ For example, Yale University's ISA-style “Tuition Postponement Option" program in the early 1970s prescribed that students pay $4 \%$ of their income in exchange for each $\$ 10,000$ in funding. But the obligation was cohort based, in that everyone was required to continue to pay (up to a cap) until the cohort as a whole repaid. High earners paid the $1.5 \mathrm{X}$ cap early on, while many graduates continued to pay for decades (the maximum term was set at a relatively high 35 years). The university elected to bail out the program in 2001.
} 
their own versions of income-contingent payments in exchange for educational funding, none of which proved workable (Shireman, 2017).

Various administrations and higher education players have revisited income-contingent repayment over the years, with a formal Income-Contingent Repayment Plan first introduced for loans funded directly by the federal government (i.e., in the Direct Loan program) during the first Clinton administration. Several additional plans in the same spirit, now called income-based repayment plans to avoid confusion with the 1990s income-contingent plan, were first introduced in 2007 and as recently as 2015. All that to say: The modern-day notion of financing investments in higher education via a share of future income is hardly new. Indeed, roughly $30 \%$ of current borrowers in the federal Direct Loan program are enrolled in one of the available income-based repayment plans for student loans. Nor are income-contingent loans a purely a U.S. phenomenon; many countries have successfully designed and implemented forms of income-contingent repayment of government-provided student loans, and the most well known of them is likely Australia's. ${ }^{10}$

\section{II.B. The Rise of Modern-Day ISAs}

The recent surge in interest in, and the availability of, ISAs likely stems from the combination of at least five main factors: 1) the rapid rise in the government's student loan portfolio (both because of the increase in the number of borrowers and in their average balances), principally during and immediately after the Great Recession, 2) the increase in the downside risk of investing in postsecondary education because of increased prices, a rapidly changing and uncertain economy, and more unequal returns to a college education (particularly for disadvantaged students), 3) the rise in IDR for government student loans and increased consumer comfort with the notion of payments based on the ex post realizations of income, 4) the recognition of some of the unintended consequences of extended repayment terms in the federal loan portfolio, which have led to delays in life events (e.g., homeownership) for some young people, and 5) the increased political and public focus on tying the investment in postsecondary education more directly to future job prospects and income. The question of whether postsecondary education and training are worth the investment has always been important, and, for the average graduate, there is little doubt - even given today's tuition — that the returns justify the implicit and explicit costs. ${ }^{11}$ But for those who happen to be unlucky in the labor market today, the high price of higher education (and the

\footnotetext{
${ }^{10}$ Under the Australian system, borrowers select one of six income-contingent repayment plans, paying between $4 \%$ and $8 \%$ of their incomes over 25 to 30 years, depending on the plan. Loan funding must be repaid, and the debt is not typically forgiven. This system exhibits low income shares over a longer period of time.

${ }^{11}$ See, e.g., Webber (2016).
} 
associated spike in debt) can be particularly devastating. Over time, the current financial aid landscape and its heavy reliance on student debt helped to create an environment in which some educational programs, students, and (philanthropic or profit-seeking) capital saw ISAs an intriguing alternative. ${ }^{12}$

\section{II.C. Purdue University Socializes the ISA Concept}

A high-profile early mover in the recent burst of ISA programs was Purdue University, with its Back a Boiler ISA program launched in fall 2016. Mitch Daniels, Purdue University president, conceived of Back a Boiler initially as a "gap-financing" mechanism, a vehicle to provide alternative funding to Parent PLUS or private student loans for families of juniors and seniors who had exhausted their eligibility for the more favorable Stafford loans. ${ }^{13}$ Offering ISAs in this context was meant to extend an incomecontingent payment feature not available to borrowers of Parent PLUS and private student loans to families averse to taking on additional (traditional) student debt. Initially, Back a Boiler was available only to upper-class undergraduate students, but the popularity of the ISA program led Purdue to extend the eligibility to sophomores and students in select health science graduate programs over the next several years.

Back a Boiler garnered significant attention from industry participants, policy circles, and the general public. It was crucial in setting the stage for postsecondary educational programs to offer ISAs more widely as a vehicle for financing higher education. As discussed previously, several other smaller ISAs preceded Purdue University's ISA efforts by several years, but they were less successful in socializing the concept of an ISA. ${ }^{14}$ In addition to the main Back a Boiler ISA backed by a return-seeking investment fund, Purdue operates a donor-backed Pave the Way program, which funds eight or nine ISA participants yearly. Pave the Way reduces students' income shares in exchange for voluntary pledges back into the program after graduation that are used to fund subsequent cohorts of participants.

Relatedly, while Purdue is perhaps the single most well-known provider of ISAs, the Back a Boiler program is not necessarily representative of the ISA market as a whole. The typical ISA program is offered not at a 150-year-old, prestigious, public university known for its scholarly research, but rather at a smaller college or university (e.g., Clarkson University, or Messiah College), or at a short-term,

\footnotetext{
${ }^{12}$ See, e.g., Palacios, DeSorrento, and Kelly (2014).

${ }^{13}$ In the ISA context, favorably termed Stafford loans from the U.S. Department of Education are typically exhausted by eligible students before they consider an ISA, such that gap financing represents total cost of attendance less grants/scholarships and Stafford loans.

${ }^{14}$ Purdue University has had a number of initiatives over the years that address access for prospective students and affordability for enrolled students (e.g., multiyear tuition freezes). In that sense, Back a Boiler is one of several tools in the toolbox in Purdue's quest for increased affordability and accessibility.
} 
accelerated, vocational or skills-based learning programs, ranging from coding academies to HVAC repair courses (e.g., Flatiron School, General Assembly, or Galvanize). In the next two sections, we will discuss the menu of features available to ISA program designers and the range of use cases for ISAs within and beyond the traditional university setting.

\section{The Anatomy of a Modern Income-Share Agreement ${ }^{15}$}

Educational programs can choose from a menu of options for both key and optional features of their ISA contract during the design stage. ${ }^{16}$ Typically, the first and most important decision, however, relates to fleshing out the goals of an ISA program. Institutions generally approach the possibility of offering an ISA in a way that is designed to address a specific set of institutional goals, as opposed to ISAs being offered for their own sake. In that sense, ISA program managers fulfill the role of assisting institutions in identifying metrics they wish to achieve (e.g., a target completion rate) and creating an ISA program designed to achieve the identified metrics.

\section{III.A. Why Do Educational Programs Offer ISAs?}

For educational institutions, objectives that drive them to consider ISAs as a funding mechanism for students typically revolve — or could revolve — around the following areas:

- Increasing access to degree programs by signaling value and removing financial barriers for constrained individuals (e.g., those who have reached loan caps, those who are ineligible for Title IV financial aid, or those who are returning to higher education after a — sometimes very — long break);

- Improving retention and completion by enabling students to remain in school (e.g., "last dollar" funding or summer-term money to catch up or accelerate degree completion) or to complete more quickly by enrolling full-time instead of part-time;

- Providing students with alternative financing options (e.g., for highly loan-averse families or where no creditworthy parent is available for private or Parent PLUS loans); and

\footnotetext{
${ }^{15}$ In this section, we focus heavily on ISAs available to students through educational programs and note that directto-student ISAs tend to be driven more by supply-and-demand forces between investors and students than any institutional objectives described next.

${ }^{16}$ For the purposes of this study, "contract" always refers to the terms of the agreement between the educational program and the student (i.e., the ISA). We recognize that a separate agreement (or agreements) governs the relationship between the educational program and any funders/investors.
} 
- Advancing strategic institutional goals along the lines of long-term program solvency, "stretching" funding ${ }^{17}$ to complement (more targeted) scholarships or grants, and other purposes.

For example, Colorado Mountain College started an ISA program called Fund Sueños, specifically for noncitizen students ineligible for federal financial aid because of their status as DREAMers. ${ }^{18}$ The University of Utah, on the other hand, tried to increase retention and degree completion by offering its Invest in U ISA to students within a year of finishing their degrees, recognizing that many of them alternate between coursework and full-time work in part because of severe loan aversion. ${ }^{19}$ A few colleges, such as Norwich University - the oldest military college in the U.S. consider ISAs an integral part of their long-term plan: to move away from an upfront tuition model and balance affordability for families, students' labor market outcomes after college, and the university's financial stability.

\section{III.B. Menu of ISA Features}

After settling on a set of objectives, an institution or investor (in the case of direct-to-student ISAs) can then specify the features most important to students from the menu. Many programs conduct extensive user testing and focus groups to determine features that would be most appealing to students at this point in the ISA design process. Setting any restriction, such as limiting the income share to a maximum of a specific percent, or having a payment window no longer than a certain number of years, will alter the set of possible parameters that can balance the target level of fund return and student protections. In this way, the program reduces the dimensionality of the contract optimization problem by setting boundaries on the possible sets of parameter solutions. Fundamentally, an ISA only works if it is simultaneously attractive to prospective students, satisfies institutional and program goals, and provides the target return on investment to the funder. Without simultaneous optimization, the program design is reduced to a game of whack-a-mole.

As discussed in more detail in the next sections, programs need to have information (or at least projections) of the distribution of realized income among program participants to come up with useful

\footnotetext{
17 "Stretching" grant or scholarship funding works like this: The educational program provides $\$ 1,000$ in ISA funding, with the understanding that some students (those with high incomes) will pay $\$ 1,000$ and others (those with low incomes) will pay less than $\$ 1,000$ after graduation. Funds that flow back into the program via ISA participant payments can then be used to fund ISAs for future students. This is more cost effective to the institution, relative to providing $\$ 1,000$ in scholarship or grant funding outright, and serves to provide assistance to more than one student using the same initial $\$ 1,000$.

${ }^{18}$ The DREAM (Development, Relief, and Education for Alien Minors) Act is a legislative option that provides legal status for qualifying noncitizen residents who entered the United States as minors.

${ }^{19}$ Students in Utah, relative to students in other states, are particularly averse to taking out student loans (Vemo Education, 2019).
} 
parameter estimates for the ISA at this stage. The institution needs to have a good sense of the full distribution of past earnings because averages tend to conceal much of the relevant detail for estimating the distribution of likely payment trajectories. Ultimately, the future success of the ISA depends heavily on the quality and length of the institutional and supplemental regional and national data on earnings patterns. It is also important for the ISA designer to accurately account for expected future career trajectories (e.g., taking into account events such as major switching, graduate education, or pauses in employment related to family obligations) and to consider the overall economic conditions for the duration of the ISA. As discussed in more detail next, even excellent data may not be enough to secure a widespread future for ISAs, if there is significant adverse selection into who decides to take up the contracts.

Some of the necessary and possible features of an ISA are outlined next. But no single element should be analyzed in isolation. Rather, the combination of features determines the predicted payment stream and ISA fund return, conditional on an expected pattern of income. We should note that direct-toconsumer ISAs can, and often do, significantly differ from the general patterns we described previously. For example, terms of such ISAs can directly or indirectly (via proxy variables) vary with the characteristics of the student or educational program.

\section{Obligations}

Income Share - The income share signifies the portion of a participant's income that must be paid toward the ISA obligation each month or year. This field varies widely across institutions and sometimes can vary across majors; theoretically, the share could vary with the characteristics of the institution (for direct-to-consumer ISAs) or the personal characteristics of the student. Income shares are typically expressed per the dollar amount (say, \$10,000) of the initial funding (also referred to as an ISA amount), taking on values as low as $1 \%$ to $2 \%$ and as high as $20 \%$ in the market today. All ISAs of which we are aware have fixed income shares, but the income share theoretically could be progressive, variable, termed as a premium over an index, and many other approaches.

Payment Rules - A common question surrounding ISAs relates to their enforceability in cases in which the ISA participant has a payment obligation based on the contract terms but fails to submit income verification documents or pay the billed amount. To illustrate the range of possible remedies, we examined contract terms pulled directly from three publicly available ISA contracts (Better Future Forward, Lambda School, and Purdue University). We include those selected terms and links to the full sample contracts in the Appendix. 
Contracts generally impose late fees or require the student to pay additional servicing costs because of nonpayment, collecting attorney fees in some cases. Some contracts stipulate that servicers may pursue judgment for the full funding amount or the payment cap, in addition to the legal and late fees; such stipulations have not, to our knowledge, been litigated in favor of the ISA provider in court thus far. Failure on the part of the student to disclose income/tax documentation for income verification purposes represents an automatic breach of contract and is referred to as an informational default. ${ }^{20}$ There is significant heterogeneity in how missed/late payments are treated. Under Purdue's contract, default does not occur until an ISA participant has made late/insufficient payments for nine consecutive months. By contrast, a breach occurs after only 90 days under the contract offered by Lambda School. Most ISA contracts include binding arbitration clauses, with a right for a participant to reject (in writing) within a certain time period from contract execution.

Employment and Income Rules - Some ISAs contain clauses requiring that participants be actively searching for a job or possibly be expected to take a job offer in their field of study, although the enforceability of such clauses is under question. Most programs - particularly at four-year institutions do not restrict employment choices of program participants in prescriptive ways. ${ }^{21}$ In theory, ISAs could also prescribe the types of income-generating activities that qualify as "earned income" for purposes of payment to avoid income concealment. In practice, all ISAs must define what types of income qualify for purposes of ISA payments, and some ISA contracts are more inclusive than others on this issue.

\section{Participant Insurance Feature: Upside Protection}

Payment Cap - The payment cap (sometimes referred to as the payment multiplier) of the amount of funding provided to the student represents the maximum amount the student will ever have to pay toward the ISA obligation. If the cap is reached, the student ceases to have any remaining ISA obligation, even if the end of the payment window for the ISA has not been reached. The cap is typically expressed as a multiple of the amount of funding received, usually ranging from $1 \mathrm{X}$ to $3 \mathrm{X}$ the ISA amount. ${ }^{22} \mathrm{~A}$ payment cap is necessary to limit the extent of cross-subsidization between participants with high incomes and

\footnotetext{
${ }^{20}$ The range of required documentation for purposes of earned income verification is considerable, from paystubs under some contracts, to monitoring of checking accounts opened with partner financial institutions mandated by the ISA program manager under other contracts.

${ }^{21}$ For comparison, all recently proposed federal legislation (discussed in greater detail in Section V) has contained specific "noninterference" clauses with regard to postgraduation employment.

${ }^{22}$ Very few ISA programs (e.g., Better Future Forward's Opportunity ISA) include internal rate of return (IRR) caps, or effective interest rate caps, that are substantially lower than what the existing multipliers would imply. Caps of that nature are designed to comply much better with loan regulation, especially usury laws.
} 
those with low incomes, such that the ISA would still be attractive to students with high earnings prospects.

\section{Participant Insurance Feature: Time Protections}

Payment Window and Number of Payments (or Payment Term) — For traditional ISA programs, the payment window typically varies between approximately two and 10 years. Within that payment window, the required number of payments (sometimes referred to as the payment term) can be significantly shorter: as short as a few months for accelerated, often skills-based programs. Longer windows offer reduced risk to programs and their investors because earnings tend to exhibit less variability but may not be as attractive to students. ${ }^{23}$ In addition, contract servicing can be more difficult in later years. Payment timelines usually combine a certain maximum length of time (number of months or years) with a certain maximum number of payments (e.g., a minimum of 48 payments over a maximum of 96 months).

For many contracts, certain nonemployment states (e.g., unemployment, enrollment in a qualified educational program, among others) count toward the payment window, but they do not count toward the required number of payments. Other nonemployment states, such as total and permanent disability or loss of employment authorization, may count toward both the payment window and the required number of payments. Payment schedules that combine the number of payments with a payment window that extends further into the future typically reduce risk for investors, but they also reduce the value of the safety-net provisions that may benefit students. In other words, these features combine to limit the number of times a student can make a "qualifying payment" (counting toward the payment window) of $\$ 0$.

\section{Participant Insurance Feature: Downside Protection}

Minimum Income Threshold - The minimum income threshold, sometimes also referred to as the deferral threshold, is the level of earnings above which individuals are obligated to make a payment on their ISA contract in a given month. Months during which an ISA participant is employed and earning less than the minimum threshold count toward the number of required payments under all ISA contracts of which we are aware. For traditional college programs, the minimum income threshold often varies between $\$ 20,000$ and $\$ 40,000$ per year, depending sometimes upon the industrial sector the workers will enter. Other types of ISAs, such as newer programs that offer ISAs with high minimum income thresholds (in part to signal high expected postgraduation incomes) can have minimum thresholds approaching six figures. No educational institution of which we are aware appears to allow this feature to vary across individual characteristics or other observable factors (e.g., family size, as under some IDR

\footnotetext{
${ }^{23}$ Many institutions report student preferences for shorter payment windows, but no systematic analysis is publicly available on this question.
} 
programs for federal student loans), but this could happen in theory. The minimum income threshold ensures that those students who realize no or low incomes after graduation pay less than the ISA amount (and in some cases, nothing at all).

We should note that most ISAs that we are aware of do not include an earnings disregard (i.e., a portion of income that is not included in the monthly payment calculations) in conjunction with the minimum income threshold. For example, under many IDR programs offered by the federal government, borrowers pay $10 \%$ of their income in excess of $150 \%$ of the federal poverty level, so the earnings disregard is $150 \%$ of the federal poverty level for such programs. This can be a significant parameter for students; with no earnings disregard and a minimum earnings threshold of $\$ 20,000$ under an ISA contract, a student who makes $\$ 20,001$ will end up with take-home pay significantly less than $\$ 20,000$, while a student who makes $\$ 19,999$ will pay nothing toward the ISA. This is a well-known issue in tax policy and labor policy circles and is the rationale why major means-tested government programs, such as the Earned Income Tax Credit, are phased out gradually rather than with "cliffs."

\section{Triggers for Dynamic Adjustments to Contract and Ongoing Program Maintenance}

Within an existing ISA program, parameters such as the income share can vary across cohorts, rather than being fixed, and can be pegged to a given rate of return for investors. ${ }^{24}$ For example, the income share for future cohorts could increase if investors are consistently receiving a negative return. On the other hand, some ISAs have adjusted the terms for future ISA contracts in favor of the student when the overall performance of a portfolio had been better than expected (e.g., by lowering the payment cap as Purdue University did two years into Back a Boiler). Across cohorts, institutions will sometimes also update the terms of new ISAs based on new information on how prior students are performing in the labor market. This can encompass more precise information about student outcomes or simply a change in market conditions because of a recession.

\section{III.C. ISA Funding Mechanisms}

A key, but less discussed or prominent feature of ISAs - at least to plan participants and the public at large - relates to the ways in which a postsecondary program receives any external funding needed for the ISA program. If any external investor funding (for-profit or philanthropic/social-impact capital) is used to support the ISA (either instead of or apart from the institution's own resources), the educational program can receive the funding for an ISA participant in a number of ways. The institution could receive $100 \%$ of the money up front, with investors absorbing the entire risk/return burden. More often than not,

\footnotetext{
${ }^{24}$ Theoretically speaking, there could be dynamic adjustment within a cohort, as there was in older ISA pilots, but it does not appear to be a feature of modern ISAs in higher education.
} 
the school receives some up-front payment (e.g., $50 \%$ or $75 \%$ of the ISA amount), then payments from students are passed to the investor until a certain threshold is reached (e.g., 7\% return for investor). The institution then receives any remaining payments after this point. The magnitude of the up-front payment is often tied to the cost of delivering education: If the direct cost of delivery is $\$ 7,000$, for example, and the tuition charged to students is $\$ 10,000$, an investor might offer $70 \%$ of ISA funding to the school up front to ensure the institution has enough funding to operate the program.

The arrangement between the investor and educational program can become complicated quickly; intermediate payments to the school can be triggered by student milestones (e.g., graduation) or be structured in alternative ways.

Funding for ISAs can be divided into three broad categories:

1. Yield-based models are funded by a profit-seeking investor looking for a return on capital. ISAs funded by return-seeking investors typically exhibit payment multipliers in the range of $2 \mathrm{X}$ to $2.5 \mathrm{X}$, and investors may require a return of about $7 \%$ to $20 \%$ (more typically, $12 \%$ to $14 \%$ ) on their capital. On the very low end of return targets, Purdue's Back a Boiler ISA is investor-funded but seeks a return commensurate with interest rates on Parent PLUS loans, or approximately 7\%. Investors are reporting that ISA coupon prices are about $2 \%$ to $3 \%$ higher than for comparable private student loan securitizations and tend to attribute the premium primarily to the incomeinsurance aspect of ISA (which do not typically exist for private student loans) and to the regulatory uncertainty associated with ISAs.

2. Evergreen funds generally rely on a combination of institutional funds, philanthropic contributions, and investor capital. These funds seek a return just high enough to replenish the fund for future generations, thus necessitating the fundraising for the ISA to be a one-time affair. ISAs funded by evergreen funds usually set multipliers in the $1.5 \mathrm{X}$ to $1.8 \mathrm{X}$ range and expect portfolio returns in the low single digits or even 0 . This funding mechanism is particularly common for nonprofit educational providers. For example, the San Diego Workforce Partnership's Workforce ISA and Purdue University's Pave the Way program rely on evergreen funds.

3. Deferred tuition models seek to recover only a share of the initial investment in the student's education, rarely the full amount. As mentioned previously, they can be viewed as "stretching" grant funding by receiving future payments in exchange for education funding from participants who do well in the job market, but not from those who do poorly. Consequently, the "return" on capital in this case is not really part of the calculation; many students pay nothing, and those students who do particularly well pay back the original funding amount or perhaps a bit more. 
The ISAs using this funding model usually exhibit multipliers in the $1 \mathrm{X}$ to $1.2 \mathrm{X}$ range, consistent with not seeking to recoup significant sums even from students who earn a high salary after graduation. For example, Colorado Mountain College's Fund Sueños has a multiplier of 1X.

Without any outside investors, schools reap the benefits of a marginal improvement in a student's income by more than recovering any institutional money used to fund his or her ISA (the payment multiplier exceeds 1X). As mentioned in the previous section, however, in an investor-funded model, institutions typically will not receive the full education funding amount until after investors have reached a certain return-on-investment threshold. This can create substantially greater incentives (both positive and perverse, as discussed in the next two sections) for institutions because the educational program will experience a zero or negative return, unless the average outcomes for participating students substantially outperform the school's cost of providing the education. An alternative viewpoint would be that the cost of delivery, rather than the sticker tuition, could be the basis for determining whether the school experiences a positive return.

In terms of attractiveness to students, because the incremental institutional funding is funneled directly into student success under the evergreen and deferred tuition funding models, we can think of these incarnations as progressively more student friendly as we move from yield-based funds toward deferred tuition models. Additionally, sometimes institutions report being selective in accepting investor capital. They generally prefer philanthropic or social impact capital at least early in the lifetime of an ISA, both for public perception considerations and because the generally higher return requirements in yieldbased funding models leave less leeway for tinkering with the program as the ISA finds its footing. That being said, a properly structured ISA program using the yield-based model can have an upside both for the school and the student from the start.

\section{Income-Share Agreement Use Cases and Experiences}

In our discussions with ISA marketplace participants, arguably the most striking finding is that no two ISAs are alike. This speaks well of the flexibility of these instruments to provide value to institutions and students with drastically different labor market opportunities, particularly when compared with the relatively rigid student loan markets. That said, some broad patterns do emerge.

\section{IV.A. ISAs at Traditional Colleges and Universities}

ISAs administered by four-year colleges, such as Purdue University or the University of Utah, tend to have longer payment windows, but they tend to require smaller income shares from students. This makes sense, given that students in these programs tend to be younger and are less likely to earn large salaries 
immediately after entering the labor market (even if they are likely to have very high earnings over the course of their careers). Funds at these schools are more likely to be evergreen or have deferred tuition than in other settings and are geared more toward gap financing than access at the admissions level, with the exception of Colorado Mountain College's Fund Sueños. In other words, students generally exhaust grant, scholarship, and subsidized government-loan financial aid before considering an ISA for the remaining cost of attendance.

There also tends to be more diversity in contract structure, often based on different degrees and programs of study within these schools. For example, Purdue offers different income shares and payment terms/windows based on the student's year in school (sophomore, junior, senior), level of study (undergraduate, graduate), and within groups of fields/majors with similar earnings profiles. ${ }^{25}$ On the other hand, the University of Utah offers the same income share to all students, but different payment terms/windows based on field of study. Other schools offer the same contract to all students with certain characteristics (e.g., GPA cutoff, qualifying majors) or do not segment the participant pool in any way. All in all, ISAs exhibit significant customization and adaptability across types of institutions, geography (especially in the determination of an appropriate minimum income threshold, the appropriateness of which can be very location specific), and over time for the same institution.

\section{IV.B. ISAs at Vocational, Skills-Based/Competency, Accelerated Learning, and Other Nondegree Programs}

ISAs provided by vocational and skills-based training programs, such as increasingly popular data science programs and coding academies (e.g., the Catalyst ISA program offered by General Assembly), tend to be much shorter and have a tight link to relatively immediate labor market outcomes. The payment term is commensurately short — as little as three to six months for some programs — and the income shares required tend to be higher than those at colleges and universities. Funds at these programs are more likely to be yield based, though we are aware of at least a handful of skills-based programs in partnership with philanthropic investors that are structured with rates of return considerably lower than purely for-profit investors.

At these institutions, the impetus for offering ISAs tends to revolve much more around expanding access. Many, if not most, do not participate in the Title IV student loan program, which means that

\footnotetext{
${ }^{25}$ Unlike most institutions, Purdue University was committed to the principle of no cross-subsidization from participants in higher-earning majors to participants in lower-earning majors. The ISA terms are the same within groups of about eight or nine undergraduate majors and priced separately for the few graduate degrees that can currently be funded using ISAs. From what we can gather, Purdue is open to the possibility of expanding its ISA to additional degree programs and majors, but it has no concrete plans to do so at the moment.
} 
students are either paying out of pocket or securing private loans. Students with ISA contracts represent only a portion of the student body (e.g., at General Assembly, the proportion is approximately 20\%) and are seen as most important for students who have either a spotty credit history or significant outstanding debt from other sources. Additionally, for some programs, offering an ISA has become a necessary tool for competing for students: Since there is no such thing as the Princeton Review rankings of HVAC or short-term software engineering programs, competitive tuition and ISA terms have come to carry significant signaling value for institutions offering these programs.

While ISAs appear to have broadened access to programs with promising improved labor market outcomes, it is important to note that access to ISAs is not universal. Plan providers tend to employ certain knockout criteria (e.g., not offering contracts to individuals with recent bankruptcies or significant defaults). Moreover, some programs will only allow individuals to take on an ISA obligation if they are able to complete rigorous testing/assignments. However, programs may waive some of the testing if tuition is paid up front. Such mechanisms greatly reduce the risk for ISA providers and investors, but they also reduce the extent to which access barriers are removed for individuals from disadvantaged or creditconstrained backgrounds.

\section{IV.C. ISAs as Tools in Public Workforce Development}

As funding for workforce development programs in the United States has fallen dramatically over the past decades, organizations engaged in this field have turned to ISAs to inject capital into public workforce development efforts. Because of the short-term, often vocational nature of these educational and training programs, many of the typical ISA features discussed previously for accelerated, nondegree programs apply in the workforce development space as well.

For example, the San Diego Workforce Partnership concentrates on outcome-focused approaches to equity and income mobility and identified its Workforce ISA model as a way to support sustainable workforce development programs through an evergreen fund. After a data collection and evaluation of program participant outcomes, the organization offered its ISA to students in a subset of its training programs - through the University of San Diego Extension - whose structure and clientele appeared to be particularly suitable for the initiative. The Workforce ISA kicks in after participants earn $\$ 40,000$ or more and requires payments of $6 \%$ to $8 \%$ over a period of three years. This ISA has proven particularly popular among immigrant and refugee participants who are ineligible for federal financial aid and are drawn to the "learn now, pay later" aspect of the program. 


\section{IV.D. Experiences of Programs and Students in Existing ISAs}

The principal goals of most ISAs tend to revolve around access to education or training, student retention, degree completion, and other objectives discussed in Section III. Overall, it appears that educational programs that have designed and offered ISAs in recent years describe broadly positive experiences after introducing their ISAs. Educational programs report better-than-expected payment patterns; students have felt positively about their ISA experiences and about the institution being incentivized to help them succeed via the risk sharing that is inherent in ISA programs. That being said, we are unable to provide concrete, causal effects measuring the performance of the ISAs against stated program goals and alternative education financing vehicles from any of the ISA providers with whom we are familiar. ${ }^{26}$

From a methodological standpoint, it is extremely difficult to causally estimate the effects of ISA programs for a number of reasons: 1) comparing student performance before and after an ISA is confounded by factors that affect outcomes but are also correlated with ISA implementation, 2) comparing ISA participants or applicants with other students does not account for selection on unobservable characteristics that may be correlated with ISA participation/application, and 3) comparing institutions that offer ISAs with those that do not fails to consider that the very nature of ISAs generally drives only the highest value-added educational programs into offering a value-aligned financial contract. We - along with many industry participants, researchers, and consumer advocates — encourage ISA providers to partner with researchers to rigorously study institution and student outcomes in this context through data analysis and, potentially, randomized experiments to shed light on early experiences in the market.

Educational programs offering ISAs report interesting second-order benefits after implementing their ISAs. First, one important benefit of offering ISAs for educational programs is the data that must be collected before and during program design and implementation and over the course of ISA payments. Institutions of higher education generally use only survey data to obtain information about employment and other postgraduation outcomes for their students. Low, and potentially biased by nonrandom response by participants, rates of survey completion can limit the collected data's usefulness. By contrast, robust data from ISA programs can be used both to identify problems in job placement among particular majors or groups of students and to provide current students with realistic information about past student experiences either explicitly or via the favorability of ISA terms. In theory, the U.S. Department of Education and the Internal Revenue Service (along with other government agencies) could link their data

\footnotetext{
${ }^{26}$ A number of publicly available research studies evaluated student perceptions of ISA programs in isolation and relative to student loans (e.g., Better Future Forward, 2019; Balakrishnan and Raj, 2019) and find generally favorable views of ISAs after providers explain the program nature in some detail.
} 
and provide universities with some of the same information gathered through the setup and administration of ISA programs. To our knowledge, no such plans exist or are being implemented at the moment.

In addition to better data collection processes, institutions report that the implementation of ISA programs increase contact between current students and financial aid offices during and following students' exploration of ISAs for education funding. This tends to result in higher rates of FAFSA completion, financial counseling, and the use of "wraparound" services, such as counseling, career development services, and connection with support programs offered by the program. ${ }^{27}$ Institutions also mention increased engagement by graduates and individuals who otherwise separate from the program, which may help the institution to provide support services for continued participant success. In addition, institutions and programs believe that better "connecting" their students with the educational institution may translate into more active and possibly philanthropically generous alumni. Of course, this increased contact can be expensive, and both precontract and postcontract servicing tends to be costlier for institutions, relative to the (admittedly lacking, particularly for federal loans) servicing of student loans for comparable populations.

\section{Theoretical Underpinnings of Modern Income-Share Agreements}

Given that the market for modern ISAs is both young and relatively small, and given the methodological challenges discussed in the previous section, there is little to no causal evidence on the benefits and risks/costs associated with ISAs for consumers, educational programs, or investors engaged in the market. Moreover, the experiences of programs and students in the current market might not be representative of a hypothetical future that may see a more widespread adoption of ISAs. We consider it useful then to discuss the major promises and pitfalls — based on economic theory and available empirical evidence from related research areas - that ISAs pose to educational programs and students in the short and long term. $^{28}$

- ISAs may provide incentives for the alignment of value between educational programs and students and may be a useful signal of program quality.

\footnotetext{
${ }^{27}$ Some ISA providers and program managers, such as Better Future Forward, explicitly set a goal of funding these wraparound services - delivered internally or with external partners - as part of the ISA program.

${ }^{28}$ For simplicity, we omit any discussion of the costs and benefits to investors or philanthropic contributors looking to participate in the ISA space.
} 
Many have argued that the current accountability framework in higher education is wholly inadequate to protect the interests of both students and taxpayers. ${ }^{29}$ While the majority of institutions are likely attempting to make decisions in the best interests of the student, there exists a striking lack of connection between monetary incentives of schools and the financial outcomes of students. ${ }^{30}$ Educational institutions receive financial aid from government and private sources up front and are not directly affected by poor student outcomes, except in extreme cases. ISAs may offer a mechanism to more directly align the incentives of colleges with their students' objectives and outcomes while allowing institutions to evolve more quickly than they have in the past. Some educational institutions currently also are uninformed and/or overly optimistic about the job prospects of graduates; ISAs may push schools to gain better quantitative data on their students' job markets so that they can better align the students' economic interests students with their educational program design and structure.

Providing an education with a greater return on investment for students can mechanically earn the school a higher profit (even if such profit is reinvested in the program at nonprofit institutions) in an ISA program. In an environment in which ISAs are a mainstream funding source, educational programs that provide students with few high-quality job prospects will be forced to either reform their curricula and placement services or else be purged from the market because of a lack of profitability (either of these is preferable to the status quo). This incentive is effectively a form of risk sharing, in which the burden of financing a student's education is shared by the institution. So the very nature of ISAs has the potential to fundamentally change the tone of the relationship between institutions and students; students appear to respond quite positively to the idea of an educational program being "in their corner" because of the built-in risk sharing aspect of many ISA programs.

ISAs can also offer schools a mechanism to signal to students that their education is likely to lead to successful job outcomes. A program that elects to offer ISAs, particularly one that has persisted for several years, can be a strong signal of quality to students in a market typically characterized more by noise than certainty. In this way, offering ISAs can be an effective marketing technique from the school's perspective and a way to guide students to the best option, even if students do not choose an ISA for education funding. Relative to other information-based signaling structures, such as the College Scorecard ${ }^{31}$ (or even a hypothetical improved version of the Scorecard, with more detailed

\footnotetext{
${ }^{29}$ For a comprehensive analysis of the entire college and student loan accountability landscape, see Robert Kelchen's recent book, Higher Education Accountability, on the subject (Kelchen, 2018).

${ }^{30}$ As we discuss later in this section, maximizing labor market outcomes is not and should not be the sole objective of students or institutions in higher education. That being said, education funding is repaid in dollars, so financial outcomes of students do and should matter.

${ }^{31}$ For more information on the College Scorecard data, visit https://collegescorecard.ed.gov/data.
} 
and useful data), ISA terms may be more effective from a signaling perspective because they are presented to families in a salient setting.

That being said, it is important to note that many families struggle to evaluate the quality of higher education programs because the diversity of programs makes this difficult and because some programs purposefully obfuscate quality metrics (as in the case of identified marketing deceptions in the for-profit sector). In other words, higher education sometimes is a credence good; if that was not the case, there would be no need to worry about aligning the incentives of education providers with student outcomes in the first place. The students least able to evaluate quality are often the most vulnerable - first-generation college, underrepresented demographics, and those facing obstacles or discrimination in the labor market — that are of particular concern to lawmakers, regulators, and society at large.

In other words, in the case of new programs without a proven track record or those with a very low marginal cost (e.g., many online programs), the signal of offering an ISA may not be correlated with quality. One concern is an institution "buying into" a market with a loss leader that misinforms consumers about the long-run benefits and costs, which is common in markets for various insurance products. This is less of a concern with traditional colleges, where the cost of education is very high and the institution incurs the costs well before it is fully reimbursed for them by student payments. With online and other low marginal-cost programs, however, a provider can offer generous ISA terms that might appear to suggest quality when it actually may simply be a way of creating a claim to be exercised via collections. ${ }^{32}$ These issues underscore the importance and necessity of clear and strong consumer protections in the market for ISAs, particularly as ISAs promulgate and the possibility of "bad actors" increases.

- ISAs can provide a private-market safety net in case of a negative earnings outcome.

\footnotetext{
${ }^{32}$ Consider a hypothetical example highlighted as a possibility by some market participants: A program starts by charging tuition of $\$ 12,000$ on a per student cost of operations of $\$ 10,000$ using traditional loans. After finding an ISA investor and servicer, the program begins charging each student $\$ 15,000$ using an ISA instead. Even with a very low maximum cap (as low as $1 \mathrm{X}$ ) and other favorable terms, the investor and program could still make a substantial return over their costs. If families are not experienced at assessing educational prices and quality, they may take on such an ISA obligation. The ISA contract would also pass any terms-based (i.e., a max multiplier) regulatory scrutiny due to terms that appear consumer friendly if one does not take into account the program cost/price. This example is not to imply that similar issues do not exist with other financing mechanisms (e.g., auto loans for dealerpriced vehicles), but rather illustrates an informational gap that ISAs cannot necessarily solve in isolation.
} 
A significant protection packaged with federal student loans is the safety net available through one of the many IDR programs. ${ }^{33}$ These repayment programs allow the borrower to pay $10 \%$ to $15 \%$ of the income they earn, with scheduled payments for individuals whose incomes are below a certain level (depending on the federal poverty level and, sometimes, family size) being $\$ 0$. This is a substantial value to students because it offers peace of mind for the risk averse and allows lowincome borrowers to pay little to nothing toward their loans, without facing the negative consequences of repayment difficulties, delinquency, and default. The typical IDR program also forgives the remaining loan balance (including any capitalized interest) after 20 years, wiping the slate clean for students who never received the return they likely envisioned from their college investment. However, under the current tax system, the forgiven amount is often considered taxable income, which may represent a significant and unexpected one-time tax burden for many borrowers.

An ISA similarly provides insurance against the worst possible labor market outcomes, but since there is no loan balance to track, students automatically owe nothing at the end of the payment window. For one, this may avoid some of the issues with tax liability that currently complicate loan forgiveness under IDR programs. Perhaps more importantly, the cancelation of the debt obligation that is inherent in an ISA contract is available to all participants without special eligibility rules (in contrast, e.g., to very complex eligibility rules for programs such as public service loan forgiveness, or PSLF). What's more, in practice the adoption of IDR has been slow and has resulted in some unpalatable consequences such as prolonged repayment terms, the psychological burden of stagnating or increasing loan balances because of negative amortization, and uncertainty over eventual cancelation of outstanding balance. Reforms of IDR programs could, at least in theory, address some of these undesirable or unintended consequences, but the potential of comprehensive IDR reform in the near future appears to be limited. For comparison, the private student loan market, typically used by families who have exhausted federal financial aid, currently offers no protections against negative income shocks. ${ }^{34}$

- ISAs are compatible with typical earnings trajectories because they have relatively lower payments early in a graduate's career.

The typical age-earnings profile for workers starts out low in the early years and peaks on average in a worker's early 50s, then declines toward retirement. Given this reality, the fixed-payment

\footnotetext{
${ }^{33}$ For a detailed discussion of most available IDR programs and the potential advantages and disadvantages of universal IDR, see, e.g., The Institute for College Access \& Success (2014).

${ }^{34}$ We understand that some lenders have considered offering optional "insurance" against low incomes for private student loan borrowers at a price tag of 2-3 percentage points relative to the no-insurance loan rate.
} 
repayment scheme (equal monthly payments over 10 years) for borrowers of private student loans and in the federal standard repayment plan can be especially burdensome to young student loan borrowers. They are forced to pay off their education at a time when their annual incomes are likely to be the lowest in their working lives. They may also be disincentivized from taking up lower paid or unpaid positions that could provide valuable training and skills for a higher future path of earnings.

Researchers have found that borrowers with federal student loans may choose the standard repayment plan even if their payments are burdensome, often because they are discouraged by the potential cost argument (that the total amount paid over the course of the loan could be higher because of more accrued interest in periods when borrowers make smaller payments) for IDR over the benefit of income insurance. ${ }^{35}$ ISAs, as well as other income-contingent and income-driven plans, better align payment burdens with student incomes because payments naturally fluctuate together with incomes; students face lower debt payment burdens in the early years and steeper ones as their incomes rise. ${ }^{36}$

In addition to accounting for lower incomes early in graduates' careers, ISAs can be customized to account for institution-, degree-, and major-specific earnings profiles, as well as geographic variation in reasonable minimum income thresholds, as mentioned previously. ISAs can thus more closely align the payment schedules to the students' specific circumstances than traditional loan programs with identical repayment terms across individuals, schools, and geographies.

- ISAs could relax credit constraints for students, particularly those with no family support and for students who take longer to complete their educations because of interruptions or major life changes (most students).

Under the current system, borrowing choices are limited for students who do not qualify for the federal student loan programs or for those who have reached their federal loan limits. Many students also attend universities where the after-grant cost of attendance exceeds federal loan limits. ${ }^{37}$ In addition, most students today are likely to take considerably more than the prescribed four years to

\footnotetext{
${ }^{35}$ Abraham et al. (2018) find that, when cost arguments are emphasized to students, they are considerably less likely to value IDR plans relative to students for whom the income insurance features of IDR are emphasized.

${ }^{36}$ Before IDR plans became commonplace for federal loans, the Department of Education offered and continues to offer two alternatives to the standard repayment plan: a) the graduated plan, with payments increasing over time, and b) the extended plan, with level payments that are lower than payments under the standard plan but extend longer than 10 years. Both plans have historically had relatively low enrollment, at $14 \%$ and $10 \%$ in 2018 , respectively (Baum et al., 2018). The various IDR plans, on the other hand, are considerably more popular at $29 \%$ of borrowers and $49 \%$ of balances in repayment in 2018 (Baum et al., 2018).

${ }^{37}$ This is the case not just at selective and typically higher-cost private nonprofit colleges but also at many public institutions. Average net tuition, plus room and board, at public universities was approximately $\$ 15,000$ in 2018.
} 
complete their degrees - particularly among the $30 \%$ of students who change their majors at least once within the first three years of enrollment — such that even those attending lower-cost schools are reaching aggregate loan limits well before graduation. Others will return to higher education after an extended time away. Students from low-income backgrounds and those without significant family financial support can be particularly vulnerable to facing barriers in accessing higher education, even after need-based grant aid. Such students are left with the less-than-satisfying options of Parent PLUS federal loans, private loans at high interest rates, or no student loans (if they lack credit history or a creditworthy co-signer) and may consider an ISA instead of not attending at all.

- ISAs may support institutional retention and degree completion goals.

A large body of research has found that the credit constraints described previously represent a significant barrier to retention and completion in higher education. ${ }^{38}$ When many people are reluctant to take on Parent PLUS or private market loans to complete their degrees, ISAs may provide at least some subset of students with a pathway to stay in school without the burdens of taking on traditional debt. This can support both institutional and student degree completion objectives, which research has shown are the primary drivers of the college wage premium. We should emphasize that this is somewhat speculative and depends on the degree to which severely credit-constrained students prefer the terms of an ISA to student loans or to dropping out.

- ISAs may encourage innovation with more effective market forces than the federal loan system but require strong consumer protections to do so.

A significant contributor to the rise of for-profit colleges and the resulting increase in student loan delinquency and default rates has been relatively easy access to federal student aid. ${ }^{39}$ For many schools, uncertainty around postcollege earnings and significant marketing budgets have kept the demand for seats high while failing to produce realized incomes that can support the repayment of the loan dollars borrowed. The Department of Education's recent decision to dilute the Gainful Employment Rule ${ }^{40}$ may exacerbate this concern because other consumer protections for students and loss minimization mechanisms for taxpayers may not be sufficiently robust. ISAs, given to their

\footnotetext{
${ }^{38}$ See, for instance, Stinebrickner and Stinebrickner (2008).

${ }^{39}$ See, for example, Looney and Yannelis (2019).

40 The Gainful Employment Rule, which went into effect in 2015, instituted disclosure, reporting, and debt-toincome ratios for students to ensure that they were not saddled with debt levels they were unlikely to repay after graduation. Institutions with significant proportions of students who did not realize incomes high enough to service debt payments lost access to federal financial aid. A brief history of the Gainful Employment Rule is summarized at https://www.insidehighered.com/quicktakes/2019/07/02/devos-issues-final-repeal-gainful-employment.
} 
fundamental feature of value alignment between student and educational program, may provide a necessary mechanism for enabling high-quality educational programs to operate (with or without federal financial aid funding) while also protecting students from unfavorable outcomes via the minimum income threshold and time protections discussed previously.

At present, a high degree of uncertainty surrounds the future regulatory and enforcement environment for ISAs, particularly with consumer protection regulations. Any financial contract with the potential for a high degree of market segmentation in payment terms is susceptible to overt or inadvertent discriminatory practices. ISA terms are selected in light of projected future earnings, but these earnings are highly correlated with a number of demographic characteristics. For loans, the criteria used to underwrite or price specific segments of the market are subject to a business justification test, which can help to reduce disparate impact of loan policies and practices on members of protected classes. ${ }^{41}$ To our knowledge, no court or regulatory agency has thus far determined that ISAs are subject to the Equal Credit Opportunity Act (ECOA), Unfair, Deceptive, or Abusive Acts or Practices (UDAAP), or other consumer protection regulations. Nevertheless, we understand that some ISA providers conduct compliance testing in the spirit of these regulations on a purely voluntary basis.

As discussed previously, it is unclear whether ISAs will be held to similar standards as loans in the future. ${ }^{42}$ While no ISA that we know of varies payment terms based on prohibited demographic characteristics, in principle, this would be possible and may be profit maximizing in certain instances. Additionally, data collection and availability may limit the ability of market participants to conduct robust regulatory compliance testing and to report to a hypothetical regulator at the moment. The designated regulator for ISA providers would have to set up any parameters of conduct and

\footnotetext{
${ }^{41}$ To date, legal scholarship on the consumer protection considerations for ISAs is limited, see, e.g., Earley et al. (2019); Fischer, Mandell, and Moyer (2019); and Rustin, Grayson, and DeGroote (2017). The topic warrants additional research and we are aware of a number of legal scholars working on these important questions.

${ }^{42}$ Senators Chris Coons, Marco Rubio, Mark Warner, and Todd Young have introduced a Senate bill (S.2114 - ISA Student Protection Act of 2019), laying out a basic consumer protection framework for ISAs, including setting a maximum income share (commensurate with payment window length), lower bound for a minimum income threshold, a maximum payment window, rules for treatment of ISAs in bankruptcy, and caps on cumulative ISA obligations for an individual. Notably, there is no maximum payment cap set in the bill as it currently stands. We should note that most substantive regulations on lenders (e.g., usury laws) are determined at the state level, so states would have the option (and some appear to be considering) of tougher restrictions on ISA providers than these proposed federal bills. The proposed law applies certain federal consumer protection laws (i.e., Fair Credit Reporting Act, Fair Debt Collection Practices Act, Military Lending Act, Servicemembers Civil Relief Act, Equal Credit Opportunity Act) to some aspects of ISAs and deems ISAs dischargeable in bankruptcy proceedings.
} 
accompanying oversight for ISAs in the future to be able to detect and avoid undesirable patterns or practices. ${ }^{43}$

- ISAs may exhibit more uncertainty over payment magnitude and payment period but more certainty over maximum income share.

Research shows that consumers tend to have varied preferences over the predictability of monthly payment amounts, length of payment window, and other features of loan programs that are also ingredients in ISA contracts (e.g., Campbell and Cocco, 2003). While stable income shares represent significant insurance against low earnings, other students may prefer other features, particularly those whose objective it is to minimize the total interest accrued while keeping payments manageable. An ISA may not be attractive to all students simply because of the uncertainty of realized payment amounts and the payment period, just as IDR programs are not attractive to all students. Ultimately, student preferences interact with providers' ability to explain the terms and structure of the ISA. Students tend to understand the concept of, say, an $8 \%$ share of their income as well or better than the concept of an annual percentage rate on a loan, but the manner in which ISAs and their loan alternatives are characterized may significantly affect student understanding and perception of ISAs (Better Future Forward, 2019). We encourage market participants to conduct new, or publish findings from existing, studies that explore the financial education aspect of the ISA program design, especially as it relates to ISA program take-up and student payment outcomes.

- Absent industry standards, ISAs may complicate credit reporting and downstream borrowing.

At present, there are no generally accepted standards in place for the credit reporting of ISAs because of their unique structure and relative novelty in a credit reporting context. Given the potential magnitude of the income obligations present in some ISAs, it is reasonable to expect that credit bureaus and lenders would have a significant interest in seeing data on ISA payments and obligations. Credit bureaus have established data fields to receive credit origination and performance data from lenders, and many of these templates do not necessarily work for performance metrics relevant to ISAs. For example, since there are multiple ways to satisfy an ISA obligation (making the required number of payments, reaching the end of the payment window, paying the maximum cap), there is really no outstanding balance or a scheduled payment (in a long-term sense) to report since payment

\footnotetext{
${ }^{43}$ The ISA Student Protection Act of 2019 designates the Consumer Financial Protection Bureau as the federal regulator for ISAs; state regulators would be able to set additional, state-specific rules. We are aware of at least five states (California, Illinois, New York, Oregon, and Washington) that have considered or are currently considering ISA-related bills, regulations, or guidance documents. In several other states, ISAs have existed under the supervision of and in close cooperation with the relevant state regulatory agency for some time.
} 
amounts vary with monthly income. Credit bureaus could treat ISA obligations similarly to, say, utilities and create a separate section of the credit report for them, then work with credit scoring firms to incorporate ISAs into credit models so consumers could benefit from the payment data collected by ISA servicers. However, this is unlikely to happen before the ISA market reaches a threshold at which dedicated procedures are worthwhile for bureaus.

Especially given the uncertainty over monthly payments and outstanding balances, underwriting and pricing loans may be somewhat complicated by the presence of one or more ISAs in a consumer's debt portfolio. Similar challenges apply to federal loans in one of the available IDR plans, and credit bureaus have been working with student loan servicers on a solution for federal loans. We understand that discussions are also underway between a number of educational ISA market players and at least one major credit bureau, as well as the Consumer Data Industry Association, on this issue. ${ }^{44}$ We hope that the proliferation of ISAs will result in industry standards surrounding credit reporting, though we realize that standardization might eventually come from regulators instead. In the meantime, the challenge of when and how to incorporate ISA payment metrics into the mainstream credit market remains.

\section{Practical Challenges to ISAs That Are Both Student Friendly and Sustainable}

In addition to the student, school, and societal costs and benefits of ISAs, it is important for stakeholders to be thinking about the short- and long-term practical challenges that ISAs face. The first set of challenges, those in the short term, are common and simply reflect the difficulties of pricing financial instruments. Different schools and sectors of higher education will be more exposed to these problems than others, but these challenges are by no means unique to the ISA market. The long-term challenges examine a hypothetical world where ISAs have become a mainstream method of financing higher education. From prudential regulatory and consumer protection perspectives, it is important that market participants and policymakers anticipate the issues that would exist in such a hypothetical future long before ISAs actually gain this type of momentum.

\footnotetext{
${ }^{44}$ That said, to our knowledge, at least one noneducational ISA provider is already reporting some aspects of their ISAs to TransUnion.
} 


\section{VI.A. Practical Challenges to Setting Up a Consumer-Friendly and Sustainable ISA}

- How can ISAs be sustainable?

Fundamentally, the terms of an ISA have to be determined so they closely follow the earnings potential of enrolled students. In that sense, it is simplistic to think of a well-designed ISA as an insurance contract protecting students from the risk of low earnings similar to an IDR program in the U.S. Instead, a well-designed ISA accounts for a range of possible outcomes for students and incorporates adequate protections for the upside earnings risk, downside earnings risk, and the maximum time horizon (as described in Section IV). To estimate the likelihood of the different student outcomes, program managers need to have data sufficiently describing the entire earnings distribution of past students and not just averages. As discussed previously, most universities unfortunately do not collect or are not able to collect high-quality data on former students.

Even with perfect retrospective data, individuals who have lower earnings potential, or are more risk averse (based on factors unobservable or unmeasurable for the program designer), may be more likely to select an ISA than an alternative form of financing. As a result, the earnings distribution of would-be enrollees can be somewhat different than the overall distribution; this concern is known as adverse selection.$^{45}$ At a minimum, this complicates the task of setting ISA terms that are both profitable (break-even for nonprofit entities) and attractive to would-be participants. Longer term, ISAs may require more significant ongoing analytics and recalibration of terms for viability. Moreover, the absence of adverse selection in early ISA markets, when the product is relatively niche, does not necessarily mean that it is not a concern in a future with widespread adoption. This is an endemic issue in consumer finance.

The problems described previously are well known to firms that attempt to price any type of insurance contract. For example, a health insurer cannot profitably set premiums based on the average health-care costs of the entire population because younger and healthier individuals are less likely to enroll in a given plan, while those who expect to need significant healthcare services are eager to enroll. As a result, insurers have an incentive to engage in risk selection through plan design (e.g., Rothschild and Stiglitz, 1976) or consumers may select plans inefficiently (e.g., Akerlof, 1970).

\footnotetext{
${ }^{45}$ Thus far, rigorous empirical evidence on adverse selection in ISA markets is slim (especially in the U.S.) and mixed. Anecdotally, school-based ISAs in the U.S.A. report ISA participant pools generally comparable to the overall student populations (e.g., Mumford, 2018). For international evidence of adverse selection in ISA take up, see, e.g., Soler (2019).
} 
- How can ISA providers design a program that works for diverse student populations? ${ }^{46}$

Pricing challenges are magnified for schools that enroll heterogeneous student populations. For instance, an important predictor of earnings is an individual's age. All else being the same, a 25-yearold is likely to make considerably less over the coming decade than a 40-year-old. If these two students are both offered an actuarially fair ISA, based on the average expected incomes, the 40-yearold is unlikely to accept the contract, and the contract for the 25-year-old would create a loss for the ISA servicer. Would regulators allow a single school to offer different contracts, based on age or factors, which might proxy for protected class status under existing law (e.g., prior job experience)? How might pricing differ based on part-time/full-time status, or for students enrolled in multiple degree programs? These are unlikely to be insurmountable challenges but will need to be carefully studied and addressed as the market grows and the potential for contracts with unfavorable terms for consumers increases.

ISA programs often thrive on essentially pooling risk over large populations, but what forms of cross-subsidization are prudent from institutional culture, moral/ethical, and regulatory standpoints? For example, schools have had to contend with whether or not to allow individuals from different programs in the same school to face different ISA terms. Again, English majors paying a higher income share than computer science majors - even if STEM, business, and certain other highearning majors also pay somewhat higher tuition and fees - is associated with the Purdue ISA model and a few others, but it is not generally the norm in the marketplace. Part of this may stem from the relatively narrow, solutions-focused design of ISA programs at traditional postsecondary institutions around access and last-mile funding, but these factors will have to be considered by programs both from a design and a consumer protection perspective. In other words, an ISA that aims to solve a specific problem (e.g., Colorado Mountain College's Fund Sueños) is likely to face different pricing challenges than ISAs designed for the student population as a whole. Relatedly, schools have tended to consider different payment amounts (same income shares) based on different career paths within a major (e.g., history major teaching elementary school versus another working in tech, who both received the same education) as part of the benefit and appeal of an ISA model relative to student loans.

\footnotetext{
${ }^{46}$ Note that these considerations are in addition to consumer protection issues discussed in Section $\mathrm{V}$ and relate primarily to the ways in which an ISA program must be designed to successfully attract participants from many different student segments.
} 


\section{VI.B. Practical Challenges as ISAs Adoption Expands}

Some challenges will not necessarily materialize unless or until ISAs grow into a mainstream form of financing postsecondary education. The purpose of this section is to anticipate potential problems that a mature ISA market might experience.

- How can ISAs be stacked and how do they interplay with other debt sources?

One potential pricing issue is stackability: How will the terms of an ISA change for students who already have ISA obligations at the same or a different institution? Should there be a limit on the cumulative income shares for an individual student (some ISAs set cumulative limits of various magnitudes, and the proposed 2019 Senate law sets the cumulative limit to $20 \%$ )? If so, and absent robust credit reporting for ISAs, there would need to be a centralized authority to keep track of students across different institutions. How would ISA obligations interact with other debt instruments, including ones that rely on IDR (e.g., federal loan programs)? Some ISA programs, such as Purdue's, have attempted to deal with the issue by providing tools that can help families understand the totality of their education-related debt obligations. Back a Boiler and other programs also limit the cumulative ISA share for students at the same institution, but we are not aware of any obstacles for individuals to hold multiple contracts from different schools.

- How might institutions respond to the presence of ISAs?

A central concern in much of the higher education accountability literature is of schools prioritizing access to students who are statistically less costly (lower income risk), effectively creditrating students at the time of admission. These types of incentives may be of even more salience in a world with significant ISA enrollment. This is a double-edged sword, as it may be outcomeoptimizing (in terms of completion and payments) for institutions to reject a candidate who would not be able to receive a benefit from the education. However, it is often easier to use crude screening devices instead of identifying such candidates. The possibility thus exists that demographics such as parents' occupation or geographic indicators could be used to proxy for the likelihood of success, and certain groups of students would be systematically disproportionally excluded from higher education.

Again, this issue is not necessarily unique to ISAs and reemerges during every round of discussions about federal student loan program accountability policies that may have the unintended effect of reducing access to higher education for particular groups of underrepresented or underserved students. The value alignment and change in tone of the relationship between educational institution and student that are inherent - and generally desirable — in an ISA setting may exacerbate the issue by increasing focus on students' (earnings) outcomes. One solution is to make our social investment 
in equality of educational opportunity explicit by using targeted scholarship and grant funding and invest into wraparound services to ensure access to higher education for groups of students of particular concern to policymakers and society writ large. We recognize that such a solution is easier proposed than actually implemented.

- How might ISAs affect student labor market choices and options?

Earlier, we mentioned one type of adverse selection in students who know they are likely to have good earnings prospects and are less likely to take an ISA contract. Moral hazard may also exist in the form of students taking lower-paying jobs, which have relatively better nonmonetary benefits, because they have the downside protection insurance available to them. For instance, a worker who owes $10 \%$ of her earned income to an ISA would rationally choose to negotiate over benefits not covered by the ISA. This could include 401(k) contributions, sick/vacation days, use of a company car, or countless other forms of nonmonetary compensation. Similarly, it could become quite commonplace for employers to implicitly or explicitly bargain with workers to shift compensation away from earned income. On the flip side, students might be more likely to consider employment opportunities, which pay less today in exchange for significant upside in the future (e.g., certain types of internships or fellowships), are riskier (e.g., create an innovative start-up), or have a public service component. And, as discussed previously, participants would not have to take any special steps to take advantage of the core payment scaling feature that is inherent in ISAs in order to accept these types of jobs.

Generally speaking, there is little evidence of strategic labor market choices in large, governmentrun income-contingent loan programs (e.g., Chapman and Leigh, 2009; Herbst, 2018), but this may be in part because of the availability of mortgage-style repayment plans and private loan refinancing, which are either unavailable or undesirable under an ISA contract. ${ }^{47}$ School-based ISA providers and servicers report no significant evidence of strategic labor market behavior on the part of plan participants thus far. This might indicate either that a) the dynamic between students and schoolbased ISAs is sufficiently unique that lessons from other financial research are not applicable, or b) the evidence will emerge only over the medium to long term, as families become more experienced or familiar with ISAs.

- How likely is it that "bad actors" could operate viable, low-value programs by taking advantage of low financial literacy or risk aversion?

\footnotetext{
${ }^{47}$ For example, most ISAs will allow prepayment but would require the student to pay the maximum cap less payments already made, which would be undesirable for most consumers.
} 
While funding ISAs certainly enhances accountability in the key ways described in Section V, it doesn't automatically make the higher education market perfectly competitive. Effective marketing will still attract some students to higher-cost, low-value programs as it does today. It is thus an open question as to whether such programs would be sustainable if they do not add much value, yet enroll students who are going to earn enough to service their ISA agreement despite receiving an education of no value. ${ }^{48}$ A related question is how students would be treated if a school closes. Would students still be responsible for a share of their income even if their program failed the so-called market test?

- How will ISA providers address participant nonpayment or fraud?

In most current ISA contracts, students are required to self-report their income on a monthly basis or have their deposit account monitored for purposes of verifying earned income. At the end of each year, ISA holders must provide documentation via a tax return, which the servicer uses to verify and reconcile past payments. Written into some of the agreements are acceleration clauses that will cause the ISA holder to become liable immediately for the full funding amount, or even the max cap of the ISA, less payments made, in the event of fraud or persistent failure to provide adequate documentation. The nascent ISA market has not yet had these acceleration features tested by the legal system in a significant way, but considerations of effective collection strategies, balanced with legal and regulatory restrictions to protect consumers from aggressive collections, will be important going forward. Likewise, timely and accurate mechanisms to verify income are central to how the ISA market functions, and any flaws or inefficiencies in the current methods are likely to be exacerbated in a world with widespread ISA usage.

- Would ISAs contribute to the codification of higher education as a purely income-generating enterprise?

Given that many of the benefits of a more highly educated society are difficult to quantify and are nonmonetary, one concern of widespread ISA usage is that it further codifies the notion of higher education as a purely income-generating enterprise. Such a shift could reduce the intrinsic motivation of individuals and institutions to pursue education as an end in itself. Could ISAs be used as an excuse for reducing public support for higher education, particularly during economic downturns? We hypothesize that government support and philanthropic contributions could sustain many socially valuable programs, at least outside of recessionary episodes, but we highlight the concern as one to consider. On the other hand, it may also be that ISAs instead simply allow administrators to bring the

\footnotetext{
${ }^{48}$ Even today, students attend institutions that deliver no value (in terms of labor market returns), so this possibility is very real. See, e.g., Darolia et al (2015).
} 
language around postsecondary education as a financial improvement closer to reflecting a change in viewpoint that has already occurred within the broader population.

\section{Discussion}

Given the intense interest in finding alternatives to the traditional student loan programs to finance postsecondary education, as well as the sheer amount of capital currently flowing into the ISA marketplace (and sitting on the sidelines watching the regulatory developments), it is clear that ISAs will be a significant topic of discussion going forward. Some view these instruments as potentially transformative of higher education finance, while others summarily dismiss them. We believe that a more nuanced view recognizes ISAs' potential to address a number of market failures of the current system but urge legislators and regulators to build important guardrails that can help to prevent harmful outcomes for students and institutions.

Generally speaking, we find that ISAs hold important promises, but some can overstate these promises since ISAs often share some of the same challenges as other forms of income-contingent payment, including (well-designed) IDR programs. On the other hand, critics highlight important consumer protection questions but tend to understate the promising mechanisms of ISAs around value alignment between educational provider and student and in drawing institutional focus more directly toward measurable student outcomes (financial and otherwise). Ultimately, ISAs are neither a panacea nor perilous, and the devil is in the details — as with all financial instruments. The goal of our study is to describe ISA programs in detail, provide an overview of early experiences with ISAs, and raise important design and legal/regulatory issues that must be addressed for the market to serve as a positive force in postsecondary education finance.

Consumer protections similar in spirit — and adapted for the unique features of an ISA framework - to existing disclosure, antidiscrimination, fair credit reporting, and other regulations, are critically necessary both to protect students and to check the incentives of potential bad actors that could sink a nascent market with high-profile abuses. We must prevent such actors from causing harm to students in ways that were all too common in past cycles of disruption and innovation in higher education, and we have been encouraged by proactive discussions of ways to prevent this issue at every industry conference we have attended. Indeed, building the data sources and data science — including rigorous statistical methods for identifying causal links between ISAs and various outcomes — will be instrumental in minimizing risk to consumers and maximizing the success of ISAs in expanding educational and economic opportunity for students. Increased data transparency, as programs offering ISAs collect rich anonymized employment and wage data on alumni, is a particularly intriguing potential 
benefit, especially if collection could be combined with periodic releases to the public that summarize the income trajectories of former students.

One key challenge for lawmakers and regulators is that, with so many contract terms at an institution's and investor's disposal, writing regulations that at the same time 1) envision most reasonably predictable means of abuse but also 2) continue to encourage innovation and investment in the sector, will be a tough needle to thread. Indeed, finding rigorous ways to weigh the expected returns generated by an ISA portfolio, relative to the benefits to plan participants, may be more comprehensive in minimizing the loopholes available to bad actors than attempting to regulate individual aspects of the contract. ${ }^{49}$ This is because measures of return to capital aggregate the potential effects of the many individual contract terms and the price charged to the student for the training (or, for that matter, the cost of delivery) into a single benchmark. ${ }^{50}$ That being said, the potential complexity of rate-of-return calculations that depend on variations in the payment waterfall can be incredibly complex, or this measure could simply be defined in a way that is no longer meaningful. This is a classic problem in the regulated utility literature, and one we imagine will receive due attention as the marketplace works toward establishing metrics and benchmarks that make sense within the framework of ISAs.

The landscape of ISAs extends far beyond what we are able to discuss within this paper. Some innovative proposals, such as Delisle (2019), envision a dramatically different future when the federal government trades in its role as the nation's sixth-largest debt holder for the role of an ISA funder and administrator that sets terms and collects payments via the tax code. In addition to the many existing papers in the literature on ISAs that introduce the idea and the foundations for ISAs, we hope to see robust studies on outcomes from the many ISA programs currently collecting payments and tracking student performance. We also encourage continued research into the myriad education funding models proposed across the political spectrum, which may have no ISA component, such as universal IDR.

Regardless of what the future holds for financing higher education, it is imperative that we learn from the lessons of the many successful and failed programs and policies that have led to the current challenges and discontent around the role of postsecondary education and its funding. Our paper contributes to this robust discussion by overviewing the ISA marketplace, discussing the theoretical

\footnotetext{
${ }^{49}$ Again, refer to the earlier example in footnote 32 of a program that sets a reasonable maximum cap, income share, etc., but charges a tuition higher than what would be charged absent an ISA program.

${ }^{50}$ For example, we understand that one state regulator considered requiring ISA funders to disclose return projections and the underlying income estimates to students. Funders would not have been penalized for inaccurate projections as long as they were truthful and transparent toward the student. It is unclear how well students would be able to assess the reasonableness of these projections, but the example illustrates only one alternative to terms-based regulations.
} 
underpinnings of the ISA model, overviewing key practical challenges for ISA design and widespread adoption, and discussing the early use cases and experiences of educational programs engaged in the space. We recognize the myriad ISAs that educational programs have designed in thoughtful and targeted ways to achieve important access, retention, and completion goals for their learner populations, and anticipate seeing new and interesting ISA variants in the near future. But we also recognize that ISAs will only be able to achieve their mission of relaxing financial constraints in terms of access to education if our country simultaneously invests considerably more into equalizing opportunity throughout the pipeline into higher education - as we should do regardless of the manner in which we fund higher education. Otherwise, we might succeed in smoothing idiosyncratic shocks to earnings via some flavor of an income-contingent financing method — ranging from ISAs to well-designed universal IDR — but continue to see students systematically disadvantaged before entering higher education fail to realize the many promises of postsecondary education and training. 


\section{Bibliography}

Abraham, Katherine, Emel Filiz Ozbay, Erkut Ozbay, and Lesley Turner. 2018. "Framing Effects, Earnings Expectations, and the Design of Student Loan Repayment Schemes," National Bureau of Economic Research Working Paper 24484.

Akerlof, George. 1970. “The Market for 'Lemons': Quality Uncertainty and the Market Mechanism," Quarterly Journal of Economics 84(3): 488-500.

Bair, Sheila, and Preston Cooper. 2019. "The Future of Income-Share Agreements: Politics and Policy," New York, NY: Manhattan Institute, https://media4.manhattaninstitute.org/sites/default/files/R-0319-SB.pdf.

Balakrishnan, Sidhya, and Daanish Raj. 2019. "DREAMer Perceptions of Student Debt and ISAs," New York, NY: Jain Family Institute, https://www.jainfamilyinstitute.org/assets/dream-us-report.pdf.

Baum, Sandy, Jennifer Ma, Matea Pender, and CJ Libassi. 2018. "Trends in Student Aid 2018," New York, NY: The College Board, https://research.collegeboard.org/pdf/trends-student-aid-2018-fullreport.pdf.

Better Future Forward. 2019. “Communicating ISAs: A Design Research Study,” Lakeville, MN, https://www.betterfutureforward.org/blog/2019/7/6/communicating-isas.

Campbell, John, and João F. Cocco. 2003. "Household Risk Management and Optimal Mortgage Choice," Quarterly Journal of Economics 118 (4): 1449-1494, https://doi.org/10.1162/003355303322552847.

Chapman, Bruce and Leigh, Andrew. 2009. "Do Very High Tax Rates Induce Bunching? Implications for the Design of Income Contingent Loan Schemes," Economic Record 85 (270): 276-289.

Darolia, Rajeev, Cory Koedel, Paco Martorell, Francisco Perez-Arce, and Katie Wilson. 2015. “Do Employers Prefer Workers Who Attended For-Profit Colleges? Evidence from a Field Experiment," Journal of Policy Analysis \& Management 34(4): 881-903.

Delisle, Jason. 2019. "How to Make Student Debt Affordable and Equitable," New York, NY: Manhattan Institute, https://media4.manhattan-institute.org/sites/default/files/R-0719-JD2.pdf.

Earley, Maria, Steven Owens, Robert Goldenberg, and Brenda Beauchamp Ward. 2019. "Income Share Agreements: How They Work and Their Place in the Federal Regulatory Regime," Washington, D.C.: Reed Smith LLP, https://www.reedsmith.com/-

/media/files/perspectives/2019/isawhitepaperseptember2019.pdf.

Fischer, Rick, Jeremy Mandell, and Elyse Moyer. 2019. "Regulatory Treatment of Educational ISAs Under Federal and Select State Consumer Credit Statutes," Washington, D.C.: Morrison \& Foerster LLP, http://media2.mofo.com/documents/190408-regulatory-educational-consumercredit-statutes.pdf.

Herbst, Daniel. 2018. "Liquidity and Insurance in Student Loan Contracts: The Effects of Income-Driven Repayment on Borrower Outcomes," unpublished manuscript. 
Kelchen, Robert. 2018. Higher Education Accountability, Baltimore, MD: Johns Hopkins University Press.

Looney, Adam, and Yannelis, Constantine. 2019. "The Consequences of Student Loan Credit Expansions: Evidence from Three Decades of Default Cycles," Working Papers 19-32, Federal Reserve Bank of Philadelphia.

Mumford, Kevin. 2018. "Student Selection into Income-Share Agreements," Purdue University Working Paper (unpublished).

Palacios, Miguel. 2018. "Financing Human Capital Through Income-Contingent Agreements," in Stuart Andreason, Todd Greene, Heath Prince, and Carl E. Van Horn, eds. Investing in America's Workforce: Improving Outcomes for Workers and Employers. W.E. Upjohn Institute for Employment Research.

Palacios, Miguel, Tonio DeSorrento, and Andrew P. Kelly. 2014. "Investing in Value, Sharing Risk," Washington, D.C.: American Enterprise Institute, https://www.aei.org/wpcontent/uploads/2014/02/-investing-in-value-sharing-in-risk-financing-higher-education-throughinome-share-agreements_083548906610.pdf.

Rothschild, Michael, and Joseph E. Stiglitz. 1976. "Equilibrium in Competitive Insurance Markets: An Essay on the Economics of Imperfect Information," Quarterly Journal of Economics 90 (4): 630-649.

Rustin, Dowse B., Neil E. Grayson, and Kiersty M. DeGroote. 2017. "Pricing Without Discrimination: Alternative Student Loan Pricing, Income-Share Agreements, and the Equal Credit Opportunity Act, Washington, D.C.: American Enterprise Institute, https://www.nelsonmullins.com/storage/7c1826e7006e6ace1243803d02579924.pdf.

Shireman, Robert. 2017. "Learn Now, Pay Later: A History of Income-Contingent Student Loans in the United States," Annals of the American Academy of Political and Social Science 671: 184-201.

Soler, Maria Claudia. 2019. "International Evidence on Income Share Agreements: Perceptions and Characteristics of ISAs Recipients," University of Illinois at Urbana-Champaign working paper (unpublished).

Stinebrickner, Ralph, and Todd Stinebrickner. 2008. "The Effect of Credit Constraints on the College Drop-Out Decision: A Direct Approach Using a New Panel Study," American Economic Review 98 (5): 2163-2184.

The Institute for College Access \& Success (TICAS). 2014. "Should All Student Loan Payments Be Income Driven? Tradeoffs and Challenges," Indianapolis, IN: Lumina Foundation, https://www.luminafoundation.org/files/publications/ideas_summit/Should_All_Student_Loan_P ayments_Be_Income-Driven.pdf.

Vemo Education. 2019. “The University of Utah's Invest in U Program,” Arlington, VA, https://vemoeducation.com/university-of-utah-isa-program/.

Webber, Douglas. 2016. "Are College Costs Worth It? How Ability, Major, and Debt Affect the Returns to Schooling," Economics of Education Review (53): 296-310. 


\section{Appendix - Sample Payment Collection Terms}

\section{Purdue Back a Boiler ISA ${ }^{51}$}

(a) Default. Without prejudice to our other rights and remedies hereunder, and subject to applicable law, we may deem you to be in default under this ISA upon: (i) your failure to make any payment in full and on time for nine (9) consecutive months; (ii) your failure to provide Formal or Informal Earned Income Documentation or Documentation for Deferment as required by Sections 6(c), 6(d) and 6(g) within one (1) year of its due date; (iii) your failure to provide us a completed and signed IRS Form 4506-T or Form 4506T-EZ (or any successor form) within thirty (30) days of the annual deadline or our separate request, as set forth in Sections 6(d) and 9; or (iv) your violation of any other provision of this ISA that impairs our rights, including but not limited to our receipt of information we deem to be materially false, misleading or deceptive.

(b) Remedies Upon Default. Subject to applicable law (including any notice and/or cure rights provided by applicable law), upon default, we may elect to (i) collect the Payment Cap, less any Monthly Payments already made and plus any outstanding fees, (ii) enforce all legal rights and remedies in the collection of such amount and related fees (including any rights available to us to set off any state tax refund) or (iii) utilize any combination of these remedies. You agree to pay our court costs, reasonable attorneys' fees, collection fees charged by states for state tax refund set-off (currently fifteen percent in Indiana), and other collection costs related to the default (including our fees and costs due to your bankruptcy or insolvency, if applicable) to the extent permitted by applicable law.

(c) Equitable Remedies. If we conclude that money damages are not a sufficient remedy for any particular breach of this ISA, then we will be entitled to seek injunctive or other equitable relief as a remedy for any such breach to the fullest extent permitted by applicable law. Such remedy shall be in addition to all other remedies available at law or equity to us.

\section{Lambda School ISA ${ }^{52}$}

a. Breach. Without prejudice to Company's other rights and remedies hereunder, and subject to applicable law, Company may deem you to be in breach under this Agreement upon any of: (i) your failure to make any Monthly Payment within ninety (90) days of the due date; (ii) your failure to report or update your Earned Income within ninety (90) days of Leif's request; (iii) your failure to provide Leif with a completed and executed IRS Form 4506-T, your social security number, or the name of your Employer(s) within ninety (90) days of Leif's request; (iv) your failure to provide details of and confirm ownership of your Approved Bank Account within ninety (90) days of receiving written notice from us or Leif of such failure; (v) your failure to provide documentation including, without limitation, copies of your federal tax returns, pay stubs, Form W-2s, and offer letters, and summaries of any non-written or oral non-cash consideration, equity, or deferred compensation arrangements as may be reasonably requested by Leif, pursuant to this Agreement; or (vi) your violation of any other provision of this Agreement that impairs Company's rights, including but not limited to, the receipt of information that Leif deems, in its sole discretion, to be materially false, misleading, or deceptive.

\footnotetext{
${ }^{51}$ Terms pulled directly from sample 2017 Purdue University's Back a Boiler ISA contract, last accessed on October 21, 2019.

${ }^{52}$ Terms pulled directly from sample Lambda School ISA contract, last accessed on October 21, 2019. "Leif" refers to Leif Technologies, Inc., the ISA program manager.
} 
b. Remedies upon Breach. Subject to applicable law (including any notice or cure rights provided under applicable law), upon breach, Company shall be entitled to: (i) collect the Prepayment Amount; (ii) enforce all legal rights and remedies in the collection of such amount and related fees (including any rights available to Company to garnish wages or set off any federal or state tax refund); or (iii) utilize any combination of these remedies. You agree to pay Company's costs of collection to the extent permitted by applicable law, including reasonable attorney fees, collection fees charged by a taxing authority for tax refund set-off, and any other fees or costs (including Company's fees and costs due to your bankruptcy or insolvency, if applicable).

c. Equitable Remedies. If Company concludes that money damages are not a sufficient remedy for any particular breach of this Agreement, then Company shall be entitled to seek an accounting, as well as injunctive or other equitable relief to the fullest extent permitted by applicable law. Such remedy shall be in addition to all other legal or equitable remedies available to Company."

\section{Better Future Forward Opportunity ISA ${ }^{53}$}

19. Breaches of this Agreement. Student and Funder shall perform all obligations under this Agreement. In the event of a breach of this Agreement, the non-breaching Party shall provide the breaching Party with notice of the breach.

19.1. Opportunity to Cure. The breaching Party shall have no less than ten (10) Business Days to cure the breach. If not cured within the specified period, the non-breaching Party may proceed in an action against the breaching Party in accordance with the section of this Agreement entitled Dispute Resolution.

19.2. Material Breaches. Without limiting the foregoing, the following shall all be deemed material breaches of this Agreement:

19.2.1. Student's failure to timely remit a Payment to the Funder.

19.2.2. Student's failure to timely remit required financial documents or updated Tax Return or other required tax documents/forms.

19.2.3. Student's failure to timely notify Funder of a change in employment status.

19.2.4. Student's failure to provide accurate and truthful information to Funder, all such information being warranted and represented as truthful, not misleading, and accurate.

19.2.5. Student's failure to present information to perform a reconciliation or to remit the Reconciliation Payment.

19.2.6. Student's failure to provide updated contact information.

19.2.7. Student's failure to provide documentation, when requested, related to unemployment.

\subsection{Results of Breach}

19.3.1. Attorneys' Fees Available in the Event of Breach. In the event of any breach of this Agreement (including but not limited to, those identified above) the non-breaching Party shall be entitled to recover attorneys' fees incurred in bringing the action, not to exceed thirty-five $(35 \%)$ of the amount recovered.

\footnotetext{
53 Terms pulled directly from sample 2019 Better Future Forward Opportunity ISA contract, last accessed on October 21, 2019.
} 
19.3.2. Fees for Late Payment. Any Monthly or Reconciliation Payment due from Student to Funder that remains unpaid shall be subject to the late Payment fees set forth in the Schedule of Fees, attached as Exhibit A.

19.3.3. Fees for Failure to Provide Required Financial Documents or Updated Tax Returns. Any required financial documents or updated Tax Returns due from Student to Funder, which Student fails to provide will be subject to the late document provision fees set forth in the Schedule of Fees, attaches as Exhibit A. If the documents are not provided within ninety (90) days of a due date, Student shall be responsible for the payment of all costs incurred by Funder in obtaining the information which may include the costs of: (i) locating student through databases, personal locating services, or private investigators, (ii) sending notices to student, (iii) retaining an attorney to locate student or file a lawsuit, or (iv) filing a suit to obtain the information.

19.3.4. Funder's Rights. Funder shall have the right to use all means available by law to collect any amounts determined due under this Agreement, including any state-court rights of levy, attachment, garnishment, and/or wage assignment." 


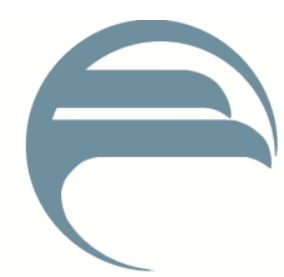

FEDERAL Reserve BANK of PHILADELPHiA

Consumer Finance Institute Discussion Paper Series

http://www.philadelphiafed.org/consumer-finance-institute 